\title{
Projection of physical conditions in the North Sea for the 21st century
}

\author{
M. Mathis*, T. Pohlmann \\ Institute of Oceanography, University of Hamburg, Bundesstr. 53, 20146 Hamburg, Germany
}

\begin{abstract}
A global climate scenario run based on the IPCC future emission scenario SRES A1B was dynamically downscaled for the North Sea, using an uncoupled meso-scale model system. The atmospheric forcing shows an increase in air temperature during the 21st century with stronger warming in winter than in summer. These trends are reflected by an increase in annual mean sea surface temperature of $\sim 1.8^{\circ} \mathrm{C}$. The strong warming in winter is the main driver for the total warming of the North Sea, as indicated by the analysis of surface heat flux components. The thermocline weakens in intensity according to the changing temperature profiles, and its mean depth slightly decreases due to lower wind speeds. The salinity in the North Sea drops by $\sim 0.6 \mathrm{psu}$ because of decreasing salinity of the inflowing Atlantic waters, increasing Baltic discharge, and higher downward surface fresh water fluxes. Some of our results disagree with other dynamical downscaling studies, as the results depend on the parent global model. In general, the downscaled projected trends qualitatively agree with the results of the coarser global model. Nevertheless, in particular, the magnitudes of the surface heat fluxes, the formation of the frontal system, and the strength and structure of the general circulation are more realistically represented in the regional meso-scale model.
\end{abstract}

KEY WORDS: Dynamical downscaling $\cdot$ North Sea $\cdot$ IPCC SRES A1B $\cdot$ Climate change

\section{INTRODUCTION}

Regional circulation models (RCMs) are useful for the study of regional dynamics in the ocean and atmosphere, such as ocean currents (e.g. Pohlmann 2006, Ådlandsvik \& Bentsen 2007, Melsom et al. 2009), or energy and fresh water cycles (e.g. Jacob 2001, Schrum et al. 2003, 2005), as well as for the projection of climate change on a regional scale (e.g. Schrum 2001, Déqué et al. 2005, Meier 2006, Ådlandsvik 2008, Holt et al. 2010). There is a wide consensus that dynamical downscaling using RCMs is the most appropriate option for regional impact studies and vulnerability analyses related to climate change (Feser et al. 2011). Adaptation measures to climate change, as opposed to mitigation policies, are an inherent local- and regional-scale issue. The restricted model domain of a RCM allows for longterm simulations with high grid resolution at compar- atively low computational costs. In general, a fine resolution is important to resolve small-scale features of the circulation, for instance near-shore processes affected by bottom topography and coastline morphology or small-scale fronts and associated baroclinic eddies and frontal jets.

In this article, results of a regionalization for the North Sea of a coupled global atmosphere-ocean simulation are presented, based on the International Panel of Climate Change (IPCC) SRES future scenario A1B (Nakicenovic \& Swart 2000) for the 21st century. The technique of dynamical downscaling is applied in a uni-directional way, that is, without feedback from the local-scale to the surrounding large-scale system. Hence, the RCM inherits any large-scale errors from the parent global model via the lateral boundary conditions (Pielke \& Wilby 2012). Beyond the mentioned advantages, the uncertainties of a given global cli- 
mate projection are therefore not reduced by the employment of an RCM.

Downscaling studies of the A1B scenario for the North Sea have been carried out by Ådlandsvik (2008) and Holt et al. (2010). In the former study, the scenario was simulated with the Bergen Climate Model (BCM), downscaled for the period 2072 to 2097 using the Regional Ocean Model System (ROMS), and compared with the period 1972 to 1997 of the control run in a time slice experiment. Holt et al. (2010) ran the scenario using the global coupled oceanatmosphere model from the Met Office Hadley Centre (HadCM3 PPE) and downscaled the results with the regional climate model from the same institution (HadRM3) and the Proudman Oceanographic Laboratory Coastal Ocean Modelling System (POLCOMS). Similar to Ådlandsvik (2008), the future period 2070 to 2098 was compared with conditions typical of 1961 to 1990.

Their results, and also our results presented here, are extracted from a dynamical downscaling of a specific future scenario realization from a coupled atmosphere-ocean global circulation model because of limited resources. However, to account for methodological difficulties of numerical modeling and the inherent uncertainty of ocean and climate projections, model ensemble studies are often invoked to utilize future projections in providing uncertainty ranges for the projected variables. Our approach is to compare individual trends with results from other publications, in particular the 2 conceptually similar studies Ådlandsvik (2008) and Holt et al. (2010), and in doing so contribute to a potentially growing literature-based ensemble study.

\section{METHODS}

\subsection{Model setup}

The North Sea future projection is carried out by means of an uncoupled dynamical downscaling with the shelf ocean model HAMSOM (Hamburg Shelf Ocean Model; Backhaus 1985, 1990, Pohlmann 1991, 1996a,c). The model domain (Fig. 1) has a meso-scale horizontal grid resolution of $\sim 3 \mathrm{~km}$ and 30 layers on $z$-coordinates in the vertical with a minimum layer thickness of $5 \mathrm{~m}$. To force the HAMSOM model, results of the coupled global atmosphere-ocean circulation model ECHAM5/MPIOM (European Center Hamburg Model 5th Generation/Max Planck Institute Ocean Model; Climate 2006) are utilized. The historical control run of
ECHAM5/MPIOM as well as the subsequent A1B scenario run have been regionalized for the greater European atmosphere by means of dynamical downscaling with the regional atmosphere circulation model REMO (Regional Model; Jacob \& Podzun 1997, Jacob et al. 2001). Results of the atmosphere model ECHAM5 have been used to prescribe the conditions at the open lateral boundaries of the regional domain, whereas the results of the ocean model MPIOM (Marsland et al. 2003, Roeckner et al. 2006, Jungclaus et al. 2006a) have been used to prescribe sea surface conditions. Atmosphere-land interactions are fully implemented in REMO and therefore are not required to be prescribed. The coarse spatial resolution of ECHAM5 $\left(\sim 1.9^{\circ}\right)$ cannot provide realistic horizontal gradients in the atmosphere, observed on the North Sea weather scale, which are well resolved by REMO owing to its finer horizontal grid resolution of $0.22^{\circ}$. These model simulations have been carried out by the Max Planck Institute for Meteorology (Hamburg). In the present study, the results of MPIOM and REMO are used analogously to drive HAMSOM. The MPIOM configuration has a horizontal grid resolution of $\sim 1^{\circ}$ in the North Sea region and 40 layers on $z$-coordinates in the vertical, while the REMO grid has 31 layers in the vertical on a hybrid coordinate system. In our study, river runoff along the North Sea coast is implemented as monthly climatological means gathered by Damm (1997) and O'Driscoll et al. (2013). Moreover, the semi-lunar $\mathrm{M}_{2}$ tide and an estimate for the global mean sea level change are imposed onto the sea surface elevation at the open boundaries. Further partial tides are not included, since the model output is stored as mean values over $2 \mathrm{M}_{2}$ periods, i.e. $24.84 \mathrm{~h}$, representing approximate daily averages, which is sufficient for investigations on the climate scale. In the North Sea, the $\mathrm{M}_{2}$ constituent gives rise to about two-thirds of the full tidal amplitude (Klein et al. 1994). Thus, major dynamical effects due to tides are well simulated since tides are included only to generate enough turbulence by non-linear interactions.

The entire simulation period is subdivided into the control period 1951-2000 to be used as a reference and the scenario period 2001-2099. However, the control run was performed in free mode, i.e. without data assimilation incorporated, to be consistent with the scenario simulation. Any modeled time series are therefore expected to deviate from observations or reanalysis data, but the climate statistics, such as the variable's long-term means and variances, should nevertheless be simulated adequately. 


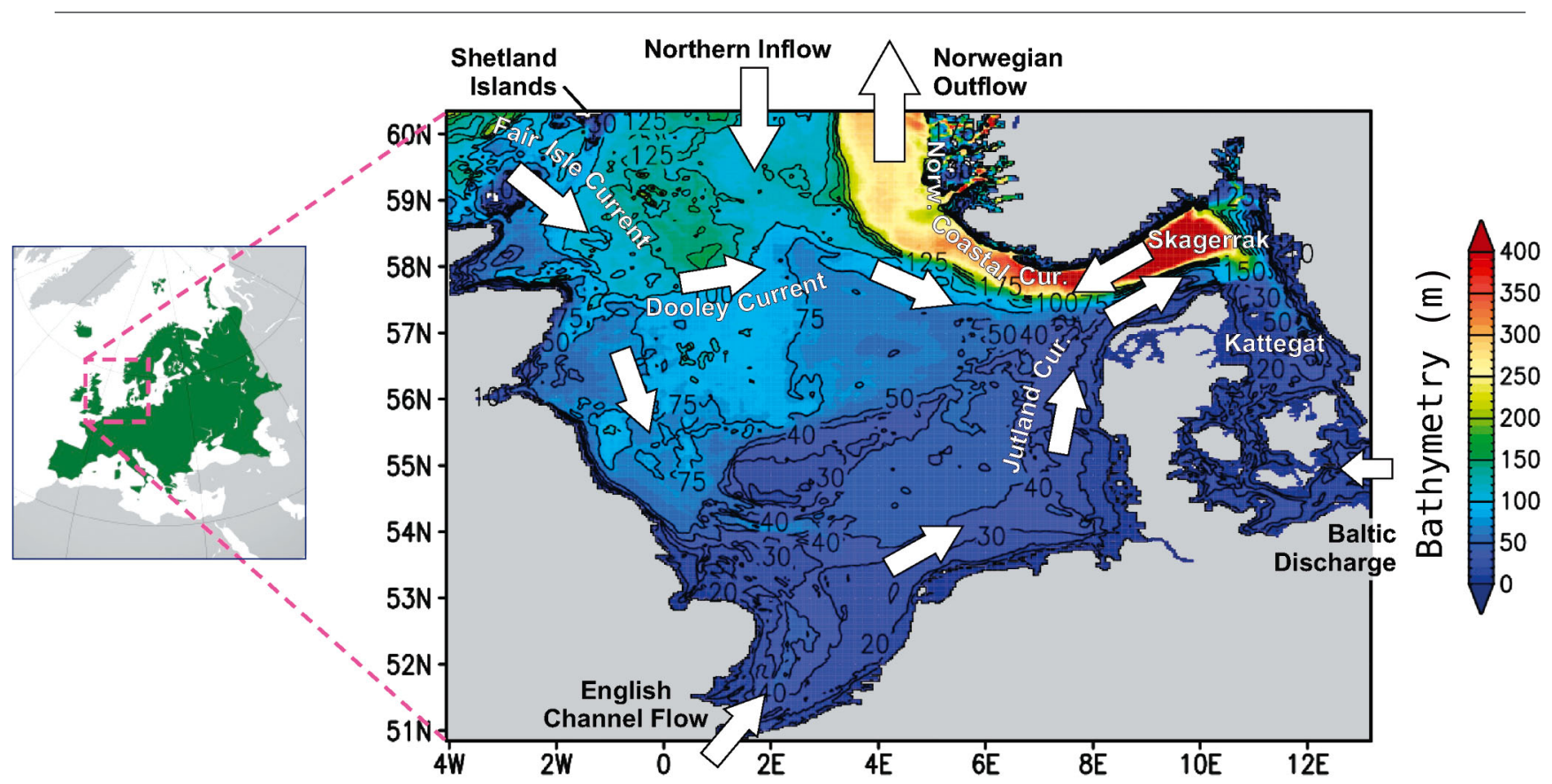

Fig. 1. HAMSOM model domain of the North Sea region with a meso-scale horizontal grid resolution of $\sim 3 \mathrm{~km}$ and a vertical grid resolution between 5 and $50 \mathrm{~m}$. A vector plot of the general circulation is shown in Fig. 2a

\subsection{Model evaluation}

A more detailed description and evaluation is given in Mathis et al. (2013), consisting of comparisons of the regionalized control run with observational data of climatological water temperature and salinity distributions as well as literature searches of volume transports, residence and flushing times, NAO correlations, surface heat and fresh water fluxes, and thermocline parameters. In general, the model results agree with the reference data. Major improvements due to the dynamical downscaling include a realistic representation of the general cyclonic circulation in the North Sea and the related volume transports and a more accurate simulation of coastal air-sea interactions, in particular with respect to heat and fresh water fluxes. Nonetheless, biases in the seasonal cycles of sea surface temperature (SST) and sea surface salinity (SSS) with respect to ocean reanalysis data and observational climatologies remain, and reach $-0.7^{\circ} \mathrm{C}$ and -0.4 psu (HAMSOM SST and SSS too low), respectively. The deviations may result from the coarser horizontal grid resolutions of the reference data and related generic differences in the discretized North Sea topography.

\subsection{Bias correction}

HAMSOM forcing data at the open lateral boundaries and at the sea surface were modified to ensure that the simulation results stay in a realistic range. The application of a linear bias correction relative to ERA40 reanalysis data (European Centre for Medium-Range Weather Forecasts) and WOA-2001 climatology (National Oceanographic Data Center) was performed to guarantee that the atmospheric and oceanic forcing data reflect the same long-term statistics for a $43 \mathrm{yr}$ reference period as atmospheric reanalysis data and climatological ocean data, respectively. The base of the correction scheme are spatial distributions of monthly deviations ( $\delta$-fields), which reflect the additive or factorial differences between the climatologies of the original forcing data and the reference data for each variable. The $\delta$-fields are imposed onto the original data, either additively or factorially, to remove the bias by bringing the climatological monthly means of the original data into agreement with those of the reference data. Details of this method are explained in Mathis et al. (2013). The straightforwardness of the correction maintains the variability as well as the long-term trends of the original uncorrected data. For the atmospheric forcing, the magnitudes of the correction amount to about $-0.7^{\circ} \mathrm{C}$ for air temperature, a factor of 0.9 for wind speed, $-5 \%$ for cloud cover, $+1 \%$ for relative humidity, and a factor of 0.7 for precipitation rate. For the oceanic forcing at the open lateral boundaries, the corrections amount to about $-1.5^{\circ} \mathrm{C}$ for water temperature, and +1.4 psu for the salinity at the Norwegian Coastal Current and -0.3 psu elsewhere. Additionally, the Baltic Sea discharge obtained from 
the global simulation and the sea surface height (SSH) gradients at the northern open boundaries have been adjusted. The coarse horizontal resolution of MPIOM is not able to resolve the strong SSH gradients along the northern boundary adequately, in particular those associated with the narrow Norwegian Coastal Current. The resulting general circulation of the North Sea is therefore substantially underestimated by MPIOM (see Mathis et al. 2013). We have improved the HAMSOM open boundary conditions by a modification of the SSH gradients. Monthly climatological hindcast values have been employed analogously to the procedure discussed above, in this case provided by a higher resolution simulation $\left(0.2^{\circ}\right)$ that covers the entire northwest European shelf.

\subsection{Scaling issues}

The horizontal scales of the forcing fields used and the HAMSOM ocean model differ by a factor of up to 9 for the atmospheric forcing and up to 24 for the open boundary conditions. As a consequence, the horizontal gradients provided by the coarser models MPIOM and REMO are not always strong enough. For example, as just mentioned, we found the limited SSH gradients to be the main reason for the underestimated MPIOM volume transports. Also, the salinity front along the Norwegian Trench, transected by the northern boundary, cannot be resolved properly in location, extension, and intensity by the coarse model. To mitigate this deficiency when forcing HAMSOM with such boundary conditions, a bias correction with data of a higher horizontal resolution $\left(0.25^{\circ}\right)$ has been applied. Flows in the atmosphere are 100 times faster than flows in the ocean, and atmospheric phenomena are on the order of days and weeks rather than months and seasons (Schlünzen \& Krell 2004). Anomalies in the wind field are one of the main causes for local anomalies in other atmospheric variables. In using $6 \mathrm{~h}$ mean atmospheric forcing fields, the forcing variables account for semi-diurnal variations known as atmospheric tides (Chapman \& Lindzen 1970), representing the highest of the dominant frequencies in the power spectra (not shown). The predominant westerly atmospheric circulation in the North Sea region frequently carries low pressure systems, associated with storms extending across the North Sea. Characteristic North Sea weather conditions are thus properly resolved by the REMO resolution, both in space and time. In the ocean, by contrast, lower current speeds and a higher density and heat capacity of sea water allow for much stronger gradients in the water column, requiring a higher spatial resolution. The gradients, however, are induced internally by ocean dynamics rather than externally by similarly strong gradients in the atmospheric forcing. Small-scale meteorological features that are not represented in REMO should be expected only very close to the coast, where their effect on the ocean is not reproduced by HAMSOM. Nevertheless, the orographic representation of land and the resulting land-sea mask are always limited by the atmospheric grid resolution, leading to inevitable errors in the atmospheric forcing.

\subsection{Median regression analysis}

For the definition of a robust and meaningful change signal, a representative linear $100 \mathrm{yr}$ trend is constructed for any time series from the median parameters of a set of 30 running $100 \mathrm{yr}$ linear regression lines, starting at every single year of the period 1971 to 2000 and consequently ending with the corresponding year between 2070 and 2099. From each linear regression analysis, 3 parameters are obtained: estimated slope of the presumed linear trend, estimated intercept of the presumed linear trend, and confidence level of the estimated slope (via a $t$-test) to address its statistical significance (e.g. Draper \& Smith 1998, p. 36-40). In depicted time series, the median of the 30 slopes is combined with the median of the 30 intercepts to construct the representative regression line to which the median of the 30 confidence levels is assigned. The resulting trend line is set into the $100 \mathrm{yr}$ period 1986 to 2085 as being the center of 1971-2000 to 2070-2099. The upper and lower quartiles of the parameter sets are then used to provide information regarding the robustness of the deduced change signal in terms of a statistical parameter range, drawn as a gray area about the representative trend. Hence, this area envelops all individual regression lines with slope and intercept values in between the upper and lower quartiles. Note that in cases of a very robust change signal, the gray area is very narrow and can even be totally hidden by the trend line (see e.g. Fig. 5). The medians of the regression parameters slope, intercept, and confidence level are determined independently of each other to avoid selecting one particular regression line but rather to obtain a representation of the whole set of 30 linear trends. This method is referred to in this study as median regression analysis.

Annual time series in this analysis assures that the results are not influenced by the strong daily and 
seasonal cycles of the considered variables. The flushing time of the North Sea is approximately $1 \mathrm{yr}$ only (Lenhart \& Pohlmann 1997, Mathis et al. 2013), and the temperature memory is also $1 \mathrm{yr}$ at the most, since the bottom water temperatures in summer are determined by the meteorological conditions of the previous winter, when the water column is vertically mixed over nearly all parts of the North Sea. Furthermore, a second order autoregressive model is applied to both the annual ocean and atmosphere time series. To fit an autoregressive process to a given time series adequately, Bayesian information criterion (Schwarz 1978) and Akaike information criterion (Akaike 1973) statistics can be used to decide among potential orders of autoregressive models (von Storch \& Zwiers 1999, Wilks 2005). Both criteria, however, yield to autocorrelation coefficients of 0 for non-zero lags for any detrended time series considered in this study, indicating the data to be best described as white noise about their long-term trends. Nevertheless, weak statistical dependences on shorter time periods cannot be ruled out completely. Another advantage of the robustness metric is that it accounts for such frequencies, since its range increases if the corresponding amplitudes influence the spread of the 30 calculated trends.

\section{RESULTS}

\subsection{Atmospheric forcing}

Trend analysis of the meteorological forcing (biascorrected REMO results) suggests the spatially averaged annual mean air temperature in the 21st century increases by $\sim 2.1^{\circ} \mathrm{C}$ with a stronger warming in winter $\left(2.3^{\circ} \mathrm{C}\right)$ than in summer $\left(1.8^{\circ} \mathrm{C}\right)$. The annual mean relative humidity increases by $\sim 1.4 \%$ over the North Sea, and cloud cover and precipitation rates also increase. In particular in summer, cloud cover significantly increases by $\sim 3 \%$, while the strongest increase in precipitation by $\sim 0.3 \mathrm{~mm} \mathrm{~d}^{-1}$ is observed in autumn. The increasing air temperature and the enhanced hydrological cycle over the North Sea reflect the global IPCC projections of a generally warmer and moister climate under the A1B scenario (IPCC 2007). Compared to results for the first half of the 21st century taken from the RCM multi-model project ENSEMBLES (van der Linden \& Mitchell 2009), the climate change signal for the North Sea air temperature simulated by REMO is slightly lower than the ensemble mean (by $\sim 0.2^{\circ} \mathrm{C}$ ), but the change in precipitation agrees well with the bias-corrected forcing data.
Furthermore, in our results, neither the mean nearsurface wind speeds nor the duration of gale wind conditions (defined here as wind speeds $>17 \mathrm{~m} \mathrm{~s}^{-1}$ over an area greater than one-tenth of the North Sea) undergo significant increase. In spring, summer, and winter, they rather decrease slightly by only about $0.3 \mathrm{~m} \mathrm{~s}^{-1}$ and $2 \mathrm{~h}$ in winter (total over the 3 months), respectively. In autumn, however, the duration of gale wind conditions increases by $\sim 8 \mathrm{~h}$, and the local maximum wind speeds increase by $\sim 0.7 \mathrm{~m} \mathrm{~s}^{-1}$. The decrease in mean wind speeds under the A1B scenario is in agreement with a reduction in cyclone activity over the North Sea, indicated by the model ensemble mean of the ENSEMBLES project. Apart from the decreasing total number of cyclones, a slightly higher frequency of extreme cyclones in autumn and winter, associated with gale wind conditions, is also projected. The incorporation of wind directions in analyzing wind density functions (Siegismund \& Schrum 2001) and wind circulation patterns in our study indicates westerly winds remain the predominant winds in the North Sea region. Significant changes in the wind density suggest a transition of easterly and southeasterly wind conditions to an even higher frequency of westerly wind conditions, particularly in spring.

\subsection{General circulation}

To address changes in the general circulation, in our study, trend analyses are applied to depthaveraged current speeds and to volume transports through various lateral sections. On a seasonal scale, the increasing westerly and north-westerly wind density in spring gives rise to an enhanced general circulation in this season with a distinctly stronger northern inflow. For the other seasons, however, the slightly decreasing mean wind speeds lead to a slightly weaker general circulation, particularly in summer and winter. While more westerly winds are also indicated in summer and autumn, the respective reductions in wind speed are associated with higher confidence levels than the increasing relative frequencies of westerly winds and hence dominate the ocean forcing.

As given in Table 1, the most significant seasonal $100 \mathrm{yr}$ changes in advective volume transports are the increasing northern inflow in spring by $\sim 21 \%$, a decreasing inflow through the English Channel in summer by $\sim 38 \%$, a weakening in the Skagerrak recirculation in autumn by $\sim 12 \%$, a reduction in the inflow through the Fair Isle Passage in winter by $\sim 10 \%$, and an increase in Baltic discharge into the North Sea by 
$\sim 18 \%$. These seasonal changes also dominate respective changes on the annual scale (Fig. 2). The annual net increase in northern inflow also slightly increases the Norwegian coastal outflow. A substantial proportion of the northern inflow reverses into the Norwegian Coastal Current soon after entering the northern North Sea, as indicated by the stream function of depth-integrated volume transports. The reduction in the Fair Isle inflow causes a similar weakening of the Dooley Current but also a weakening in the south-eastward flow along the western side of the Norwegian Trench and, with this, a weakening in the Skagerrak recirculation. A westward intensification in northern inflow is indicated by a strengthening of the inflow east of the Shetland Islands and increasing southward-oriented current speeds in the central North Sea. The changes in depth-averaged current speeds in the entire northern North Sea including the Skagerrak are statistically significant.

\subsection{Sea surface temperature and heat fluxes}

Annual mean volume-averaged water temperature in the North Sea increases by $\sim 1.7^{\circ} \mathrm{C}$ (Fig. 3) with robustness of $[1.6,1.9]$, estimated from median regression analysis. The stronger warming in air temperature in winter than in summer is reflected by similar changes in water temperature. The SST increases in winter by $\sim 2.0^{\circ} \mathrm{C}$, while it increases in summer by $\sim 1.5^{\circ} \mathrm{C}$, averaging to an annual mean SST increase of $\sim 1.8^{\circ} \mathrm{C}$ with robustness of [1.7, 1.9].

The spatial distribution of SST changes in winter (Fig. 4) is strongly influenced by differential heating due to the local bathymetry and a similar spatial distribution of air temperature change (not shown). The shallow southern and eastern North Sea undergo maximum warming, up to $2.8^{\circ} \mathrm{C}$, which is additionally influenced by the expected stronger warming trend of the continental mainland. In summer, however, the warming of the sea surface is much more uniformly distributed, since the heat uptake from the atmosphere is widely confined to the surface layers of the stratified water column. The gradients toward the continental mainland thus do not occur.

The semi-annual period spring/summer is characterized by a positive net surface heat transfer from the atmosphere into the North Sea, whereas autumn/ winter is characterized by a negative net surface heat transfer from the North Sea to the atmosphere. Considering the individual surface heat flux components given in Table 2, the continuously weaker cooling in the cold seasons is the main driver for North Sea warming.

Significantly increasing mean cloud cover in spring and summer by up to $\sim 3 \%$ causes a decrease in ingoing short wave radiation by $\sim 5.5 \mathrm{~W} \mathrm{~m}^{-2}$, bringing about less net heat input at the sea surface by $\sim 1.4 \mathrm{~W}$ $\mathrm{m}^{-2}$. Since the warming in the atmosphere in winter is stronger than the warming in the ocean in summer, the SST drop in winter becomes lower, so the air-sea temperature difference converges (Fig. 5). The consequently decreasing sensible heat flux in autumn and winter by $\sim 6.8 \mathrm{~W} \mathrm{~m}^{-2}$ results in less net heat loss by $\sim 8.3 \mathrm{~W} \mathrm{~m}^{-2}$.

Advective heat flux from the Atlantic Ocean is determined indirectly by subtracting the total surface heat flux from the change in total heat content of the North Sea. Contributions to the heat budget from river runoff, precipitation, and sea level change are in the order of tenths of a percent and hence can be neglected. The calculated advective heat flux thus represents the net heat exchange through all open lateral boundaries, which is approximately equivalent to the net heat exchange with the North Atlantic.

The ratio of advective heat flux to surface heat flux in the North Sea amounts to about 1:6 in summer and 1:34 in winter, and a positive amount of heat is carried

Table 1. Representative $100 \mathrm{yr}$ trends of annual and seasonal mean in- and outflows $\left(1 \mathrm{~Sv}=10^{6} \mathrm{~m}^{3} \mathrm{~s}^{-1}\right.$; values are rounded to $10^{-3} \mathrm{~Sv} 100 \mathrm{yr}^{-1}$ ) through various sections in the North Sea (trends relative to the control run in brackets). Positive and negative trends always refer to an increase or decrease of the flow designated in the first column, respectively. Bold values highlight the seasons of maximum trend for each transport section. See Fig. 1 for geographic references

\begin{tabular}{|lcrrrr|}
\hline $\begin{array}{l}\text { Trends of volume transports } \\
\left(\text { Sv } 100 \mathrm{yr}^{-1}\right)\end{array}$ & Annual & Spring & Summer & Autumn \\
\hline Northern inflow & $+0.051(+6 \%)$ & $\mathbf{+ 0 . 1 3 4}(\mathbf{+ 2 1} \%)$ & $+0.061(+6 \%)$ & $+0.029(+3 \%)$ & $-0.006(-1 \%)$ \\
Fair Isle inflow & $-0.025(-7 \%)$ & $+0.005(+2 \%)$ & $-0.017(-6 \%)$ & $-0.026(-7 \%)$ & $\mathbf{- 0 . 0 5 5 ( - 1 0 \% )}$ \\
English Channel inflow & $-0.011(-14 \%)$ & $-0.009(-15 \%)$ & $\mathbf{- 0 . 0 2 3 ( - 3 8 \% )}$ & $-0.005(-6 \%)$ & $-0.007(-6 \%)$ \\
Skagerrak outflow & $-0.043(-5 \%)$ & $+0.075(+12 \%)$ & $-0.078(-9 \%)$ & $-\mathbf{0 . 1 1 3}(\mathbf{- 1 2} \%)$ & $-0.057(-6 \%)$ \\
Baltic discharge & $+0.001(+6 \%)$ & $-0.002(-9 \%)$ & $+0.001(+10 \%)$ & $+0.001(+10 \%)$ & $+\mathbf{0 . 0 0 3}(+\mathbf{1 8} \%)$ \\
Norwegian outflow (total) & $+0.017(+1 \%)$ & $\mathbf{+ 0 . 1 3 2}(\mathbf{+ 1 4} \%)$ & $+0.026(+2 \%)$ & $-0.007(-1 \%)$ & $-0.079(-5 \%)$ \\
\hline
\end{tabular}




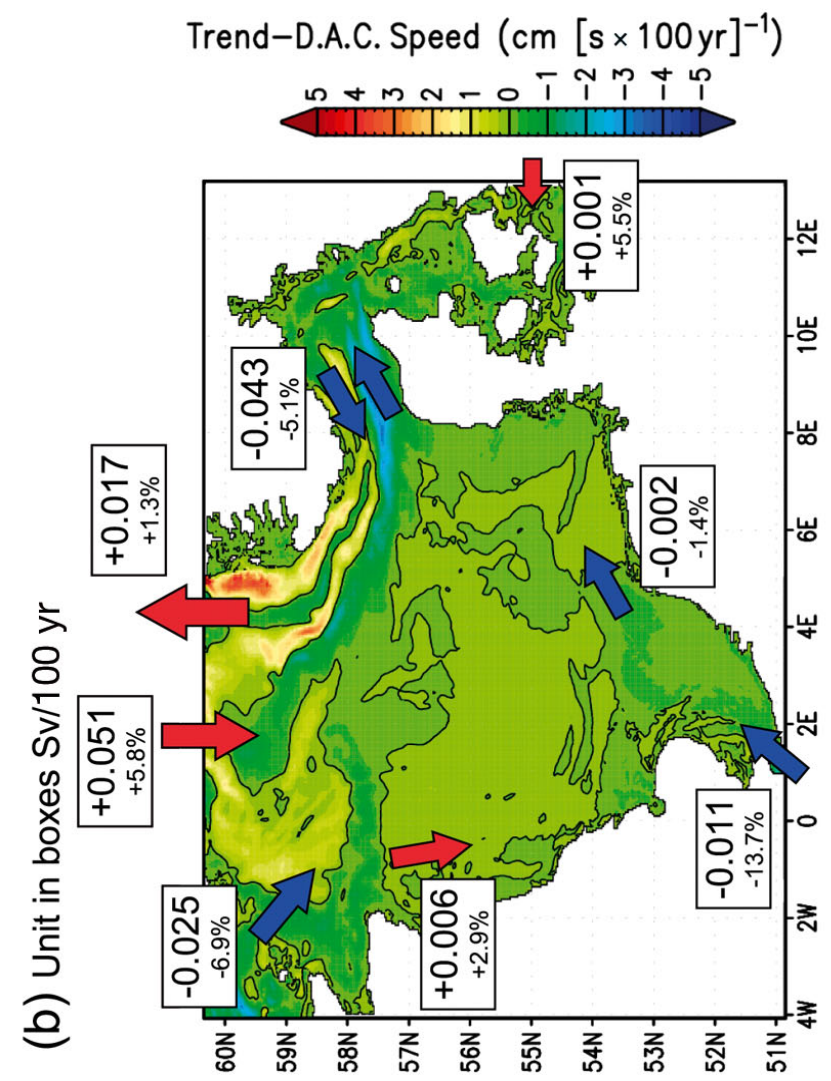

Conf.Level-D.A.C.Speed (\%)

응ㅇㅇㅇㅇㅇㅇㅁ유유응
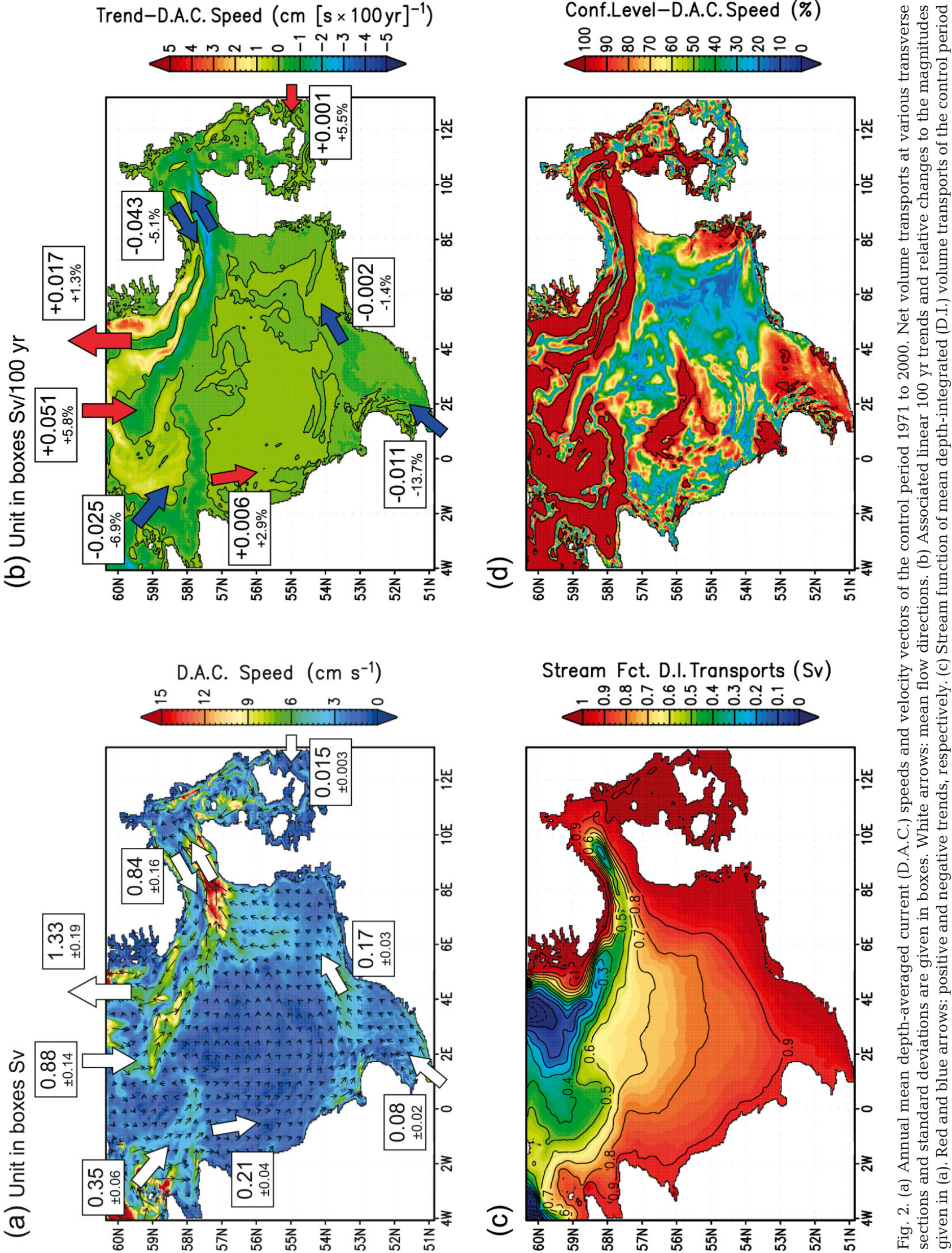

Stream Fct. D.I.Transports (Sv) o $\infty .0$.

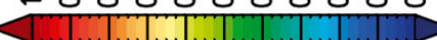

in

过总离

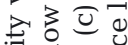

ت्ञ

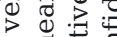

उ

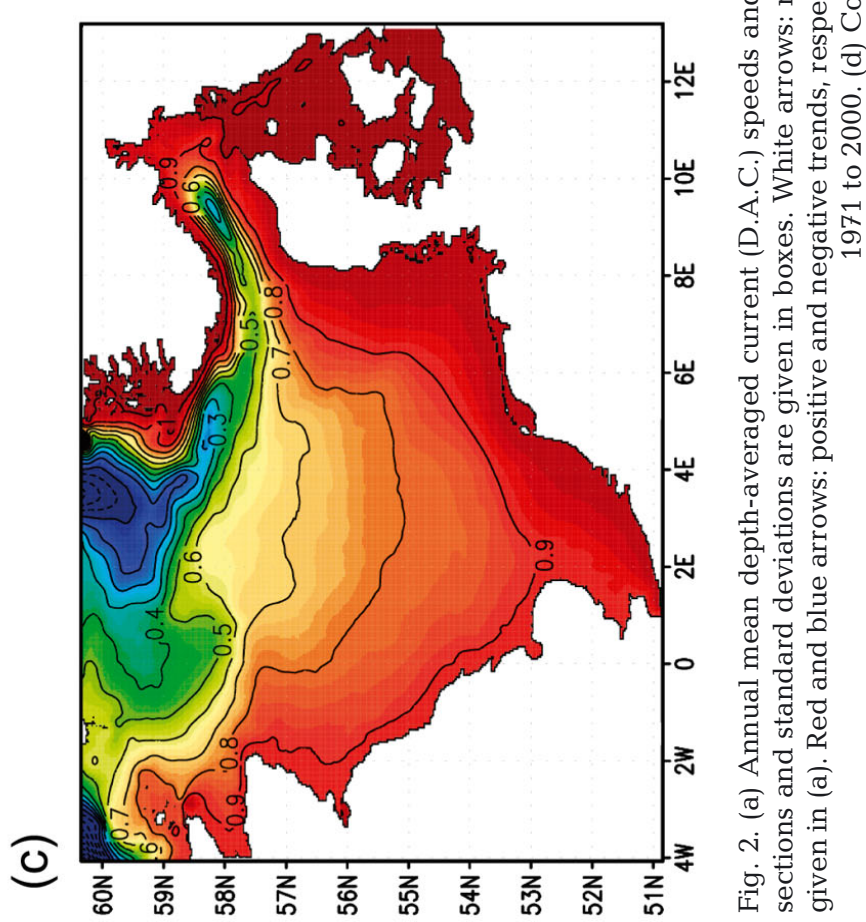




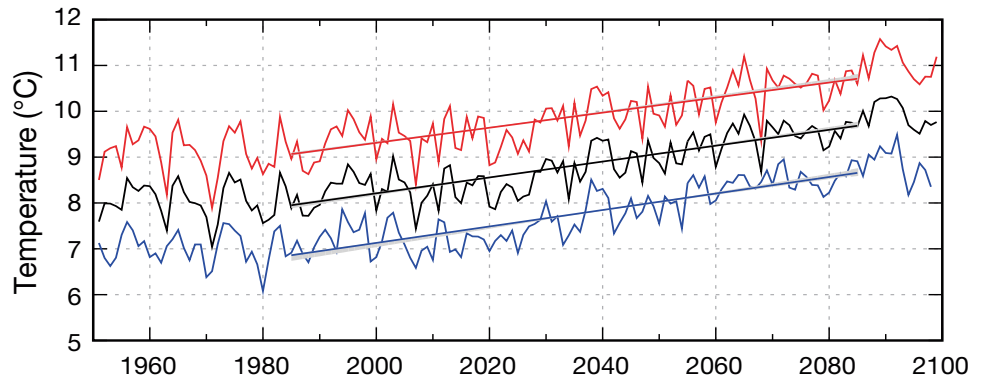

Trends and Confidence Levels:

Summer: $\Delta=+1.64[+1.59,+1.75]^{\circ} \mathrm{C} 100 \mathrm{yr}^{-1}, \mathrm{P}=99[99,99] \%$ Winter: $\Delta=+1.8[+1.73,+2]^{\circ} \mathrm{C} 100 \mathrm{yr}^{-1}, \mathrm{P}=99[99,99] \%$

Annual: $\Delta=+1.73[+1.67,+1.86]{ }^{\circ} \mathrm{C} 100 \mathrm{yr}^{-1}, \mathrm{P}=99[99,99] \%$

Fig. 3. Time series of annual (black) and seasonal (red: summer, blue: winter) volume-averaged water temperature. Representative $100 \mathrm{yr}$ trends $(\Delta)$ and associated confidence levels (P) are given with statistical ranges in brackets. Grey shadings around the trend lines illustrate the

robustness of the representative trends, explained in Section 2.5

from the Atlantic Ocean into the North Sea in both seasons (see e.g. Otto et al. 1990, Becker \& Pauly 1996, Hjøllo et al. 2009). Remarkably, the corresponding $100 \mathrm{yr}$ trends suggest a decrease in advective heat input by $\sim 2$ TW in summer and winter. The mentioned temperature increase of $\sim 1.7^{\circ} \mathrm{C}$ results from a persistently imbalanced heat budget of only $\sim 0.1$ TW. The reduction in annual net surface heat loss by $~ 3.5$ $\mathrm{W} \mathrm{m}^{-2}$ corresponds to an increase in total surface heat flux by $\sim 2.1$ TW and therefore fully balances the reduced advective heat input in summer and winter. The net heat input of $\sim 0.1$ TW finally leads to an increase in the annual mean heat content of $\sim 7 \mathrm{MJ} \mathrm{m}^{-3}$.

\subsection{Thermocline}

In ocean modeling, the North Sea thermocline can be defined as the maximum vertical temperature gra- dient in the water column, exceeding the threshold of $0.1 \mathrm{~K} \mathrm{~m}^{-1}$ (Pohlmann 2006, Meyer et al. 2011). Its maximum spatial coverage is mainly determined by the local bathymetry and tidal amplitude and is therefore not subject to significant change in the 21st century. Time series analyses of the mean and maximum depth of the thermocline (Fig. 6) well reflect the slight changes in seasonal mean and maximum wind speeds. In our analysis, the thermocline depth is defined relative to the sea surface. According to the model results, the mean depth of the thermocline is decreasing under the A1B scenario by $\sim 0.2 \mathrm{~m}$, i.e. the thermocline is rising because of decreasing mean wind speeds in spring, summer, and autumn. The maximum depth, on the contrary, is increasing by $\sim 2.4 \mathrm{~m}$ because of higher maximum wind speeds and more frequent gale wind conditions in autumn. Both the mean and maximum intensity of the thermocline are decreasing by about 2 and $5 \%$, respectively, induced by the stronger warming in winter than in summer. Since the temperature of the deeper waters in summer is determined by the water temperature of the preceding winter, the temperature difference between warm surface waters and underlying cold waters is also decreasing because of the major warming in winter.

Analysis of the thermocline duration from its formation in spring to its disappearance in autumn suggests a prolongation of the thermocline period by $\sim 6 \mathrm{~d}$, which can be attributed to the slightly lower mean wind speeds in autumn and particularly to the weaker heat loss to the atmosphere.

In Fig. 7, the representative $100 \mathrm{yr}$ trends are further analyzed at monthly scales. Corresponding
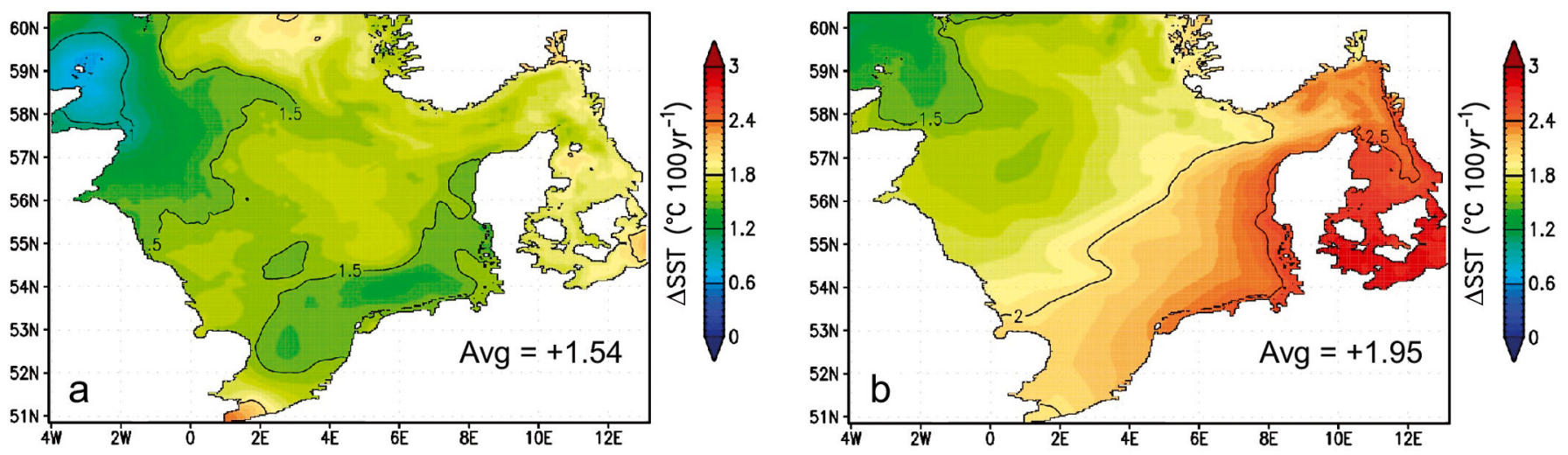

Fig. 4. Seasonal representative $100 \mathrm{yr}$ trends of sea surface temperature (SST) for (a) summer and (b) winter. Mean given at bottom right 
Table 2. Representative 100 yr trends of semi-annual surface heat flux components (short and long wave radiation, sensible and latent heat flux), calculated from bulk formulas (trends relative to the control run in brackets). Quantities driving the heat flux components are given in the last column. Trends most influencing the total heat fluxes are highlighted. Drivers most influencing the heat flux components are underlined. Upward and downward pointing arrows indicate increases or decreases. The mean sensible heat flux, for example, is positive in spring and summer (heat input to the ocean); hence, a positive trend increases its impact (Sens HF $\uparrow$ ). In autumn and winter, however, the mean sensible heat flux is negative (heat loss to the atmosphere), and a positive trend thus decreases its impact (Sens HF $\downarrow$ )

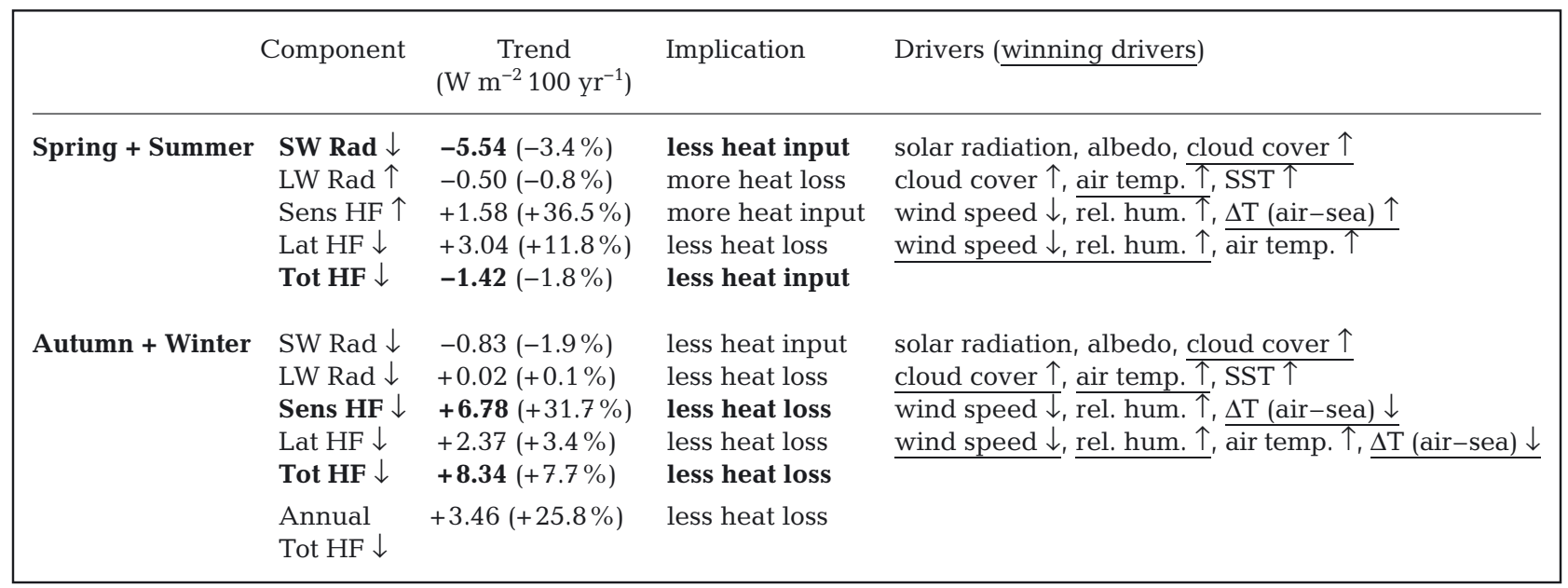

means for the control period 1951 to 1980 are shown by Mathis et al. (2013). The changes in relative frequency indicate that the thermocline develops more often in its southern and western peripheral regions, particularly in spring and summer (May and July).

\subsection{Salinity}

Seasonal distributions of changes in the 21st century largely reflect the distinct salinity drop of all inflowing water masses from the North Atlantic by $\sim 0.4$ psu in combination with minor changes in associated volume transports. The atmospheric forcing under the A1B scenario is marked by an intensifying global hydrological cycle, which leads to enhanced moisture transports from the tropics to high latitudes, resulting in a considerable freshening of the Atlantic Ocean north of $\sim 40^{\circ} \mathrm{N}$ (Gröger et al. 2013). The largest salinity drop of the North Sea inflows is observed for the English Channel flow (by $\sim 0.9 \mathrm{psu}$ ). In the eastern North Sea, more low-saline waters enter the Skagerrak because Baltic discharge increases by $\sim 1000 \mathrm{~m}^{3} \mathrm{~s}^{-1}$, and the induced salinity drop is supposed to be underestimated since in our simulation the salinity of Baltic discharge is kept constant by applying monthly present-day climatologies. Changes in surface fresh water fluxes indicate lower evaporation rates in summer, due to lower wind speeds and higher relative humidity, and higher precipitation rates in winter, to yield an increase in the total surface fresh water flux into the

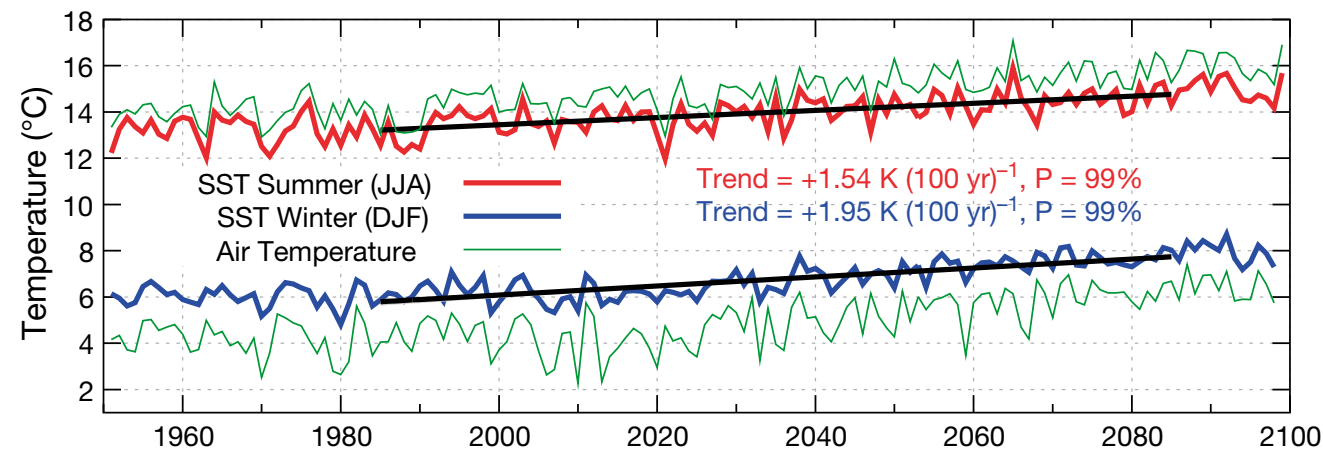

Fig. 5. Time series of sea surface temperature (SST) for summer (red) and winter (blue), representative $100 \mathrm{yr}$ trends, and the associated time series of air temperature (green) 
North Sea by $\sim 60 \%$. Increasing precipitation rates in the 21st century are also expected for the Baltic Sea and its catchment area, causing a significant freshening of the Baltic discharge (Schrum 2001, Meier 2006, Bárdossy \& Pegram 2011).

According to our model results, the total volumeaveraged salinity in the North Sea decreases under the A1B scenario by $\sim 0.6 \mathrm{psu}$ in the 21 st century with a minimum salinity of $\sim 33.5$ psu in the 2070s (Fig. 8). The most pronounced salinity drop is indicated in the Skagerrak because of the increasing Baltic discharge and lower transport rates of saline North Sea waters into this region.

\subsection{Sea surface height}

Being a volume-conserving model, the MPIOM cannot account for a global rise in mean sea level. For the HAMSOM simulations, estimates of the different components of global sea level rise are thus added to the sea surface elevation at the open boundaries. Steric expansion is calculated from the global MPIOM temperature distribution, global deglaciation is extrapolated from observations given by Solomon et al. (2007), and the balance between Greenland and Antarctic ice sheet dynamics is estimated in a model study by Jungclaus et al. (2006b). Respective time series are shown by Mathis et al. (2013). Regional deviations from the global mean sea level change are not considered in the present study, owing to relatively high uncertainties (Slangen et al. 2012). The total mean sea level rise of $\sim 0.5 \mathrm{~m}$ under the A1B scenario resulting from the 3 global components nevertheless fits well with the projected IPCC ensemble mean for the North Sea region of approximately 0.4 to $0.6 \mathrm{~m}$, where estimates of all regional components but ocean currents are included.

Apart from the global mean sea level change, decreasing flow speeds along the Norwegian Trench because of the weaker general circulation in summer, autumn, and winter induce weaker horizontal $\mathrm{SSH}$ gradients perpendicular to the flow direction. In spring, however, the increase in westerly wind conditions gives rise to an enhanced general circulation and increased flow speeds along the Norwegian Trench, which consequently induce stronger horizontal SSH gradients in this season. Furthermore, the increase of westerly wind conditions leads to a maximum total SSH increase of up to $\sim 0.6 \mathrm{~m}$ in the southern and eastern North Sea due to more frequent wind surges. A similarly pronounced SSH rise in the eastern North Sea is observed in winter, which can be attributed to the thermo- and halo-steric effects due to the strong seasonal increases in local temperature and Baltic discharge, respectively.
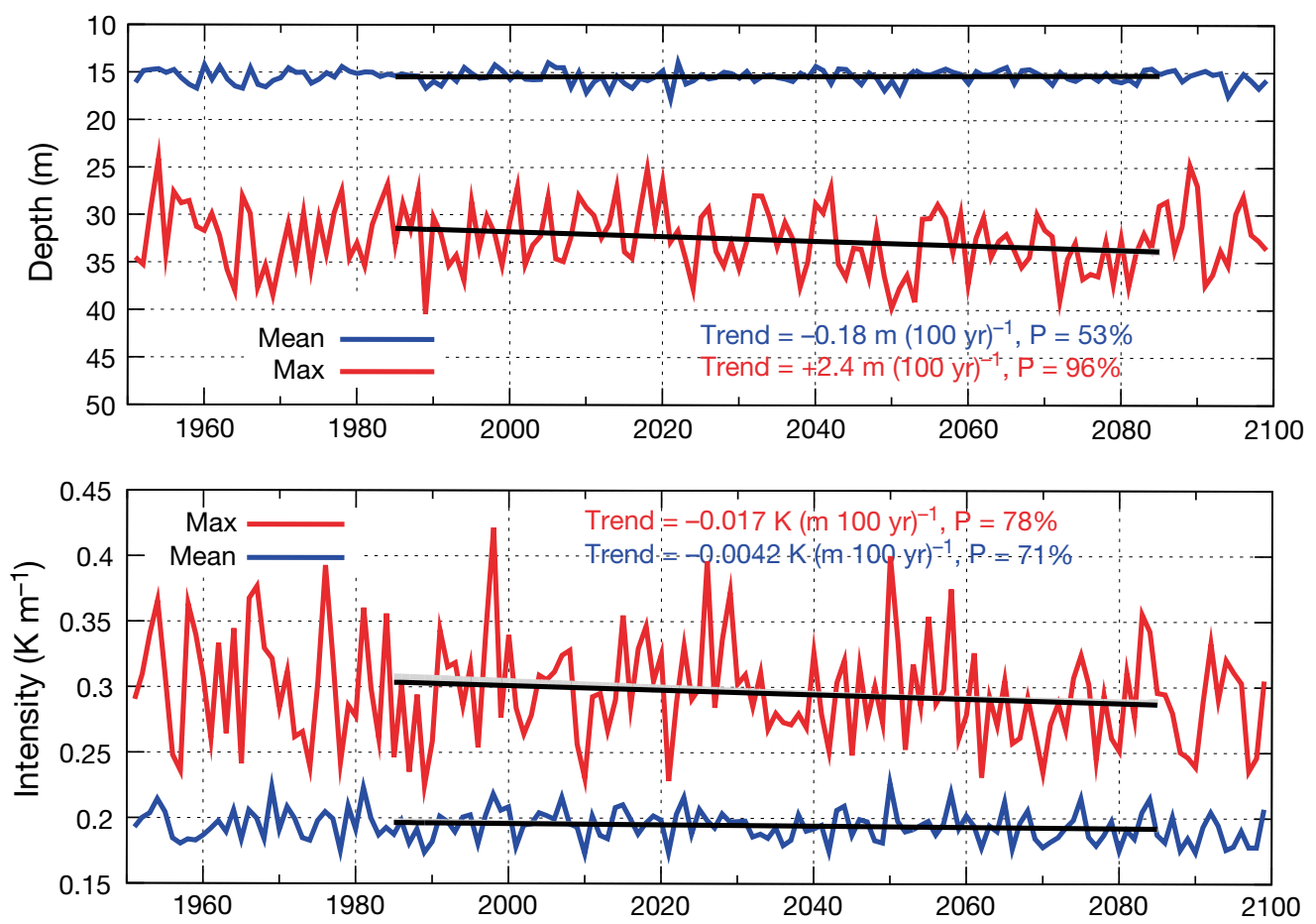

Fig. 6. Mean and maximum depth (top) and intensity (bottom) of the thermocline over the whole stratification period. Representative linear $100 \mathrm{yr}$ trends are also shown. Grey shadings around the trend lines illustrate the robustness of the representative trends, explained in Section 2.5 

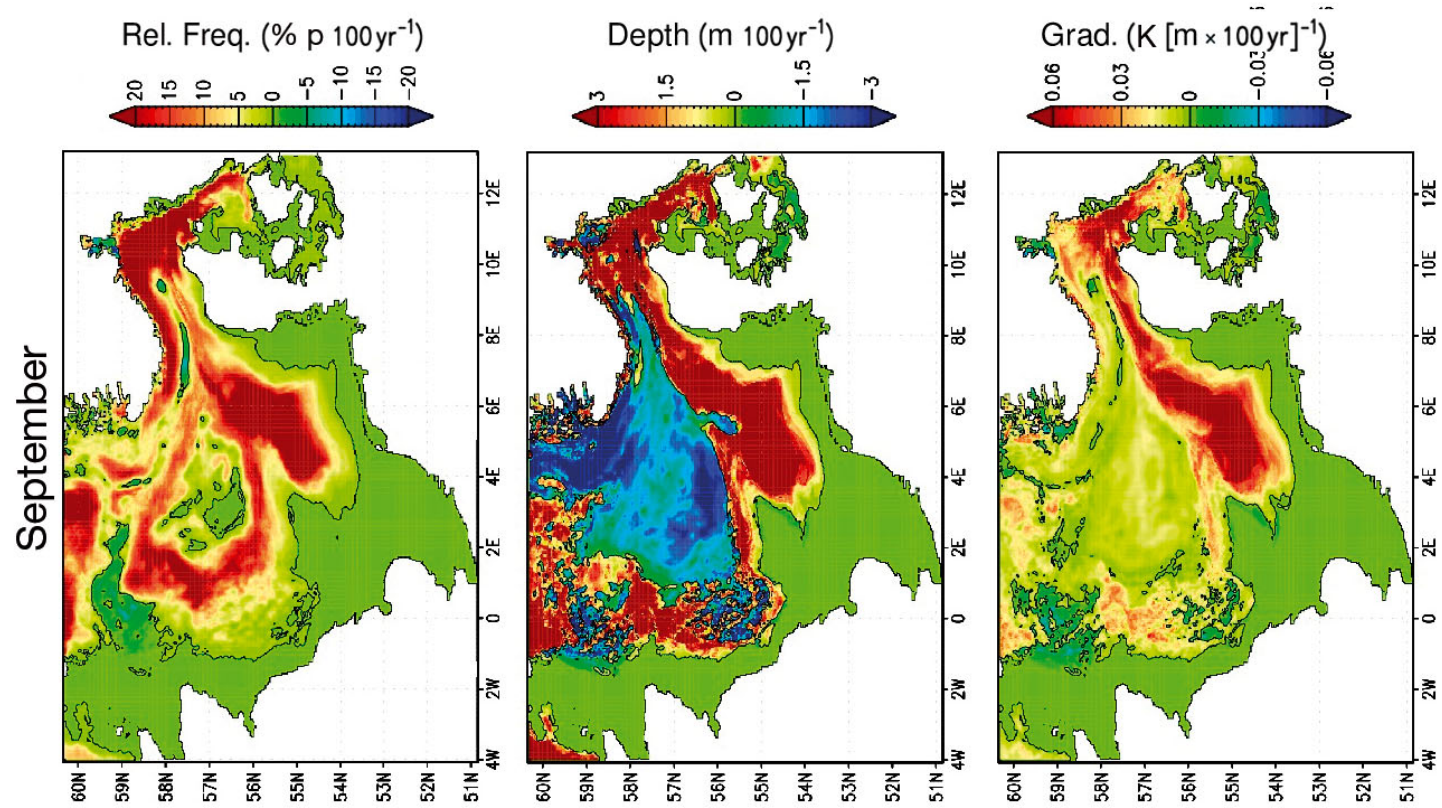

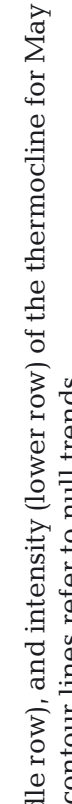
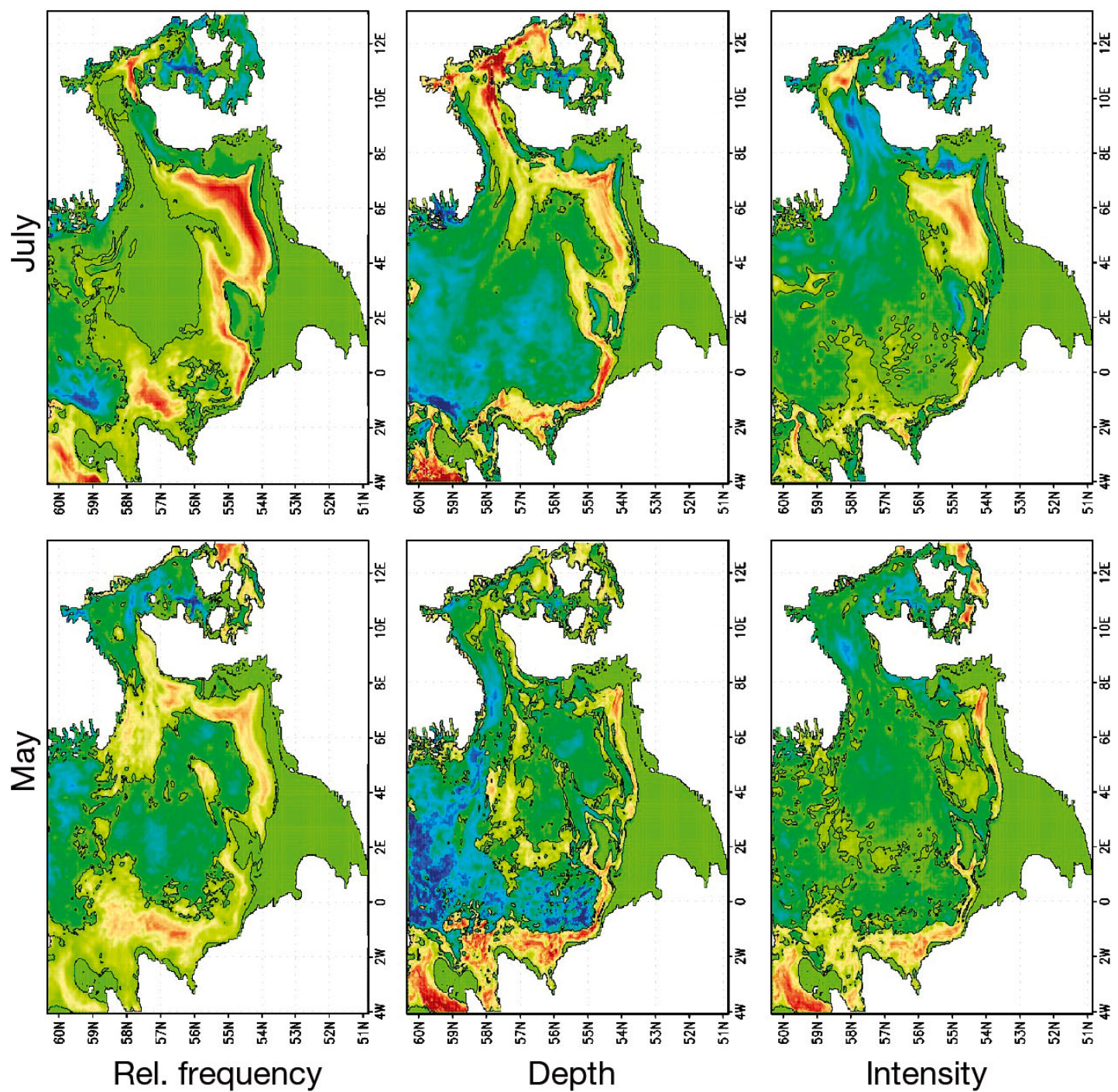

年

5.

흄

8

고.

究

营.

妾苞

过

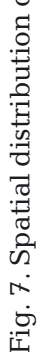




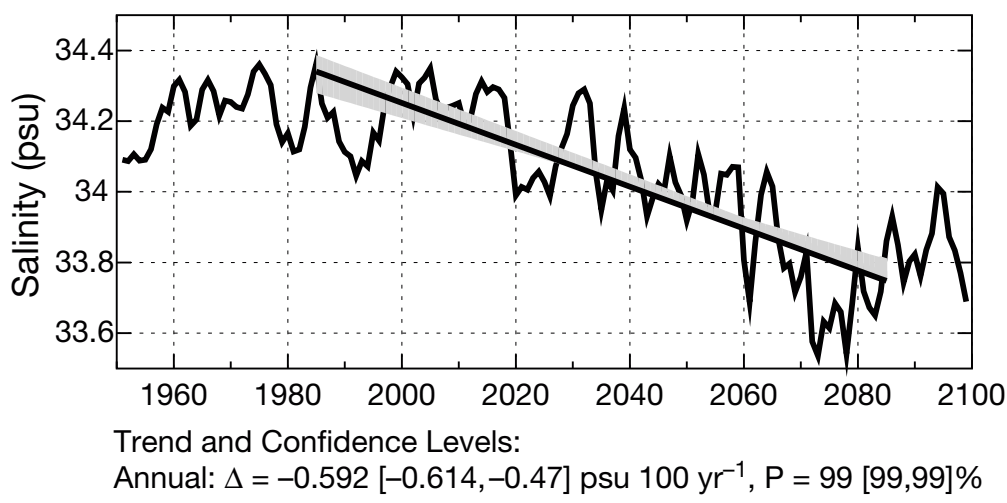

Fig. 8. Time series of annual volume-averaged salinity. Seasonal time series are not exhibited since their deviations from the annual time series are very small. Representative 100 yr trend $(\Delta)$ and associated confidence level $(\mathrm{P})$ is given with statistical ranges in brackets. Grey shading around the trend line illustrates the robustness of the representative trend, explained in Section 2.5

\section{DISCUSSION}

In general, simulated long-term trends are subject to large uncertainties, often on the same order of magnitude as both the ensemble means and the sensitivity to critical parameters (Delhez et al. 2004) and can even show opposite signs (Meier 2006). Nowadays, global and regional model systems often fail to accurately reproduce present climate for the control run (van der Linden \& Mitchell 2009), which strongly increases the spread between model results. A strength of the present study is the initialization of the scenario run with a thoroughly evaluated, biascorrected control run.

Using a Monte Carlo variance partitioning approach, the choices of GCMs and RCMs in dynamical downscaling studies were quantified by Déqué et al. (2012) as other major sources of uncertainty in climate projections. Their results suggest that for model runs until the end of the 21st century, it is more important to address the range of GCM uncertainty, whereas for future runs closer to the present day, the RCM uncertainty dominates. An overview of various climate change signals is given in Table 3, extracted from results of the parent global model ECHAM5/ MPIOM as well as of the regional models REMO and HAMSOM.

As reported by Mathis et al. (2013), the applied dynamical downscaling accurately reproduces longterm statistics of the present North Sea climate state and therefore improves the results from the parent global ocean model. The meso-scale grid resolution of HAMSOM enables a detailed and reliable representation of shelf sea dynamics, which global models can- not yet provide. In the shallow southern North Sea, the higher horizontal resolution of HAMSOM allows for more realistic horizontal temperature gradients, and hence for more reasonable local extremes (see Mathis et al. 2013, their Fig. 6). The higher vertical resolution permits a better representation of the thermocline structure. In summer, the vertical temperature gradient in the water column is weaker in the global model by a factor of $\sim 2$, which drastically reduces the stratified area. The depth and intensity of the thermocline determines the amount of heat taken up by the North Sea in summer and therefore crucially influences the surface heat fluxes. The formation of the complex frontal system in the North Sea and also the strength and structure of the general circulation are sensitive to both the horizontal and vertical grid resolution (see Mathis et al. 2013, their Figs. 7 \& 12). For these reasons, the RCM has a better representation of volume and heat transports, enabling a more reasonable structure of the general circulation and of the distribution of characteristic water masses. The differences in the projected changes of SST, given in Table 3, point out that in our study, the more accurate simulation of heat fluxes by the RCM leads to higher and lower temperature trends in winter and summer, respectively, than suggested by the GCM.

Another strength of the present study is the use of median regression analysis to address the robustness of inferred climate change signals and associated

Table 3. Winter (Wi) and summer (Su) climate change signals (rounded values) according to the A1B scenario, simulated by the global model ECHAM5/MPIOM and by the regional models REMO and HAMSOM, for volume-averaged seawater temperature (Vol-avr T), sea surface temperature (SST), volume-averaged salinity (Vol-avr S), and nearsurface air temperature (Air T). Horizontal grid resolutions are given in brackets

\begin{tabular}{|c|c|c|}
\hline & $\operatorname{MPIOM}\left(\sim 1^{\circ}\right)$ & HAMSOM $(\sim 3$ km) \\
\hline Vol-avr T & $\begin{array}{l}\mathrm{Wi}+1.8^{\circ} \mathrm{C} 100 \mathrm{yr}^{-1} \\
\mathrm{Su}+1.7^{\circ} \mathrm{C} 100 \mathrm{yr}^{-1}\end{array}$ & $\begin{array}{l}\mathrm{Wi}+1.8^{\circ} \mathrm{C} 100 \mathrm{yr}^{-1} \\
\mathrm{Su}+1.6^{\circ} \mathrm{C} 100 \mathrm{yr}^{-1}\end{array}$ \\
\hline SST & $\begin{array}{l}\mathrm{Wi}+1.8^{\circ} \mathrm{C} 100 \mathrm{yr}^{-1} \\
\mathrm{Su}+1.7^{\circ} \mathrm{C} 100 \mathrm{yr}^{-1}\end{array}$ & $\begin{array}{l}\mathrm{Wi}+2.0^{\circ} \mathrm{C} 100 \mathrm{yr}^{-1} \\
\mathrm{Su}+1.5^{\circ} \mathrm{C} 100 \mathrm{yr}^{-1}\end{array}$ \\
\hline \multirow[t]{2}{*}{ Vol-avr S } & 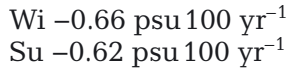 & $\begin{array}{l}\text { Wi -0.61 psu } 100 \mathrm{yr}^{-1} \\
\text { Su -0.57 psu } 100 \mathrm{yr}^{-1}\end{array}$ \\
\hline & ECHAM5 $\left(\sim 1.9^{\circ}\right)$ & $\operatorname{REMO}\left(0.22^{\circ}\right)$ \\
\hline Air $\mathrm{T}$ & $\begin{array}{l}\mathrm{Wi}+2.6^{\circ} \mathrm{C} 100 \mathrm{yr}^{-1} \\
\mathrm{Su}+1.8^{\circ} \mathrm{C} 100 \mathrm{yr}^{-1}\end{array}$ & $\begin{array}{l}\mathrm{Wi}+2.3^{\circ} \mathrm{C} 100 \mathrm{yr}^{-1} \\
\mathrm{Su}+1.8^{\circ} \mathrm{C} 100 \mathrm{yr}^{-1}\end{array}$ \\
\hline
\end{tabular}


confidence levels. Time slice analyses, in contrast, do not provide explicit information about the statistical significance of putative trends. While the signalto-noise ratio of the time slices are often used to test for confidence levels under the assumption of stationarity (e.g. Ådlandsvik 2008, Holt et al. 2012), the lead time of the projected time slice and the variance of the intermediate period are not taken into account for a single-model and single-scenario experiment (Hawkins \& Sutton 2009). In using median regression analysis, we introduce an alternative quantification of climate change signals. The method provides more information about the projected trends than conventional approaches, addressing the difficulty of assigning a meaningful number to a longterm change in a chaotic time series with substantial variability. The robustness quantifies the sensitivity of the calculated trends to the individual time period and serves to reduce the importance of precision and accuracy, whereas the confidence level quantifies their statistical significance. Note that our method relies on the theory of ordinary linear regression analysis, which is a simplifying application to the mostly, though weakly, exponential time series at hand.

\subsection{General circulation}

The comparison of changes in the general circulation of the North Sea reveals that the increasing northern inflow under the A1B scenario agrees with the 2 conceptually similar studies by Ådlandsvik (2008) and Holt et al. (2010), while a reduction in the Skagerrak recirculation is also indicated by Ådlandsvik (2008).

The increasing northern inflow can be attributed to a trend toward more westerly winds in the North Sea, in agreement with the ensemble mean of the ENSEMBLES project. The complex changes in the wind conditions probably result from changes in the northern polar front, driven by the effect of arctic amplification (Francis \& Vavrus 2012). An accumulation of heat energy in the arctic, as particularly observed in the last decade, causes the polar front to move northward and the associated westerly winds to slow down. Indeed, the strongest temperature increase in both the ECHAM5/MPIOM results and the IPCC A1B ensemble mean (IPCC 2007) is projected for the arctic region, and a poleward shift of extra-tropical storm tracks is also recognized, indicating that the effect of arctic amplification is captured by the GCMs.

\subsection{Sea water temperature and heat fluxes}

In our study, the seasonal changes in water temperature coincide with the stronger warming of air temperature in winter than in summer. The $100 \mathrm{yr}$ trends of annual mean volume-averaged water temperature and SST amount to $+1.7^{\circ} \mathrm{C}$ and $+1.8^{\circ} \mathrm{C}$, respectively. According to Ådlandsvik (2008), the same trends amount to $+1.4^{\circ} \mathrm{C}$ and $+1.7^{\circ} \mathrm{C}$, while statistical significance is ascribed to the proposed changes since the standard deviation intervals of the 2 time slices do not overlap. The considerably stronger warming in SST than in volume-averaged temperature results from the maximum warming occurring in spring and summer for the dataset of Adlandsvik (2008) rather than in winter, as in our study. In Holt et al. (2010), the SST increase in the 21 st century is quantified as 2 to $3^{\circ} \mathrm{C}$, also with a stronger warming trend in summer than in winter. Recently, another model study concerning the impact of the A1B scenario on the northwest European shelf was performed by Gröger et al. (2013) with a subtly stretched configuration of the global MPIOM model, providing a higher horizontal grid resolution in the North Sea $(\sim 10 \mathrm{~km})$ and the adjacent North Atlantic than the standard configuration $\left(\sim 1^{\circ}\right)$. Results of their study suggest the annual mean SST in the North Sea increases by nearly $2^{\circ} \mathrm{C}$ in the 21st century.

Our analysis of the individual surface heat flux components and the atmospheric parameters involved in the HAMSOM bulk formulas yields a reduction in surface heat input into the North Sea in summer due to increasing cloud cover but also a reduction in surface heat loss in winter due to the strong warming trend of the atmosphere. The resulting weaker cooling of the water column in winter induces a temperature increase, which finally also leads to a significant warming in summer, even though the net surface heat flux in summer is decreasing. Moreover, the quantification of changes in advective heat flux through the open boundaries yields a reduction in advective heat input into the North Sea both in summer and winter, in agreement with Holt et al. (2010). However, the reduction in annual net surface heat loss exceeds the reduction in advective heat input, affirming the conclusion of the warming in the winter atmosphere to be the main driver for the total warming in the North Sea. Nonetheless, this result distinctly relies on the heat flux changes extracted from the particular model run presented here and must be expected to be inconsistent with the results from Ådlandsvik 
(2008) and Holt et al. (2010), owing to their projected stronger warming trend in summer rather than in winter. On the annual scale, though, both studies accord with the result that a drop of advective heat input is compensated by a greater rise of heat input due to changes in surface heat flux. In our study, the stronger warming trend in winter than in summer is already indicated by the parent global model ECHAM5/MPIOM for both the ocean and the atmosphere (see Table 3) and is in agreement with the IPCC A1B ensemble mean for most parts of the northern hemisphere, including the North Sea region. The discrepancy with Ådlandsvik (2008) and Holt et al. (2010) is thus likely to originate from different results of the involved GCMs, supporting the above-mentioned conclusion by Déqué et al. (2012). In particular, variables related to the fresh water cycle, like cloud cover and humidity, and hence short wave radiation, are associated with the largest uncertainties in climate models (Bader et al. 2008).

\subsection{Thermocline}

Considering the stronger warming trend in summer than in winter suggested by Ådlandsvik (2008) and Holt et al. (2010), both studies may indicate an intensification of thermal stratification (in contrast to our results) because of the resulting stronger vertical temperature difference between the surface and bottom water. Similar conclusions are drawn in Holt et al. $(2010,2012)$ from changes in potential energy anomaly (PEA), that is, the energy required to vertically mix the entire water column. However, such metrics do not yield information about the depth and intensity of maximum vertical gradients, as also noted by Holt et al. (2010). Moreover, the PEA is sensitive to local sea level changes (Hein 2012) and hence influenced in our study by all the factors determining the sea level, in particular the imposed global mean sea level rise. Thermocline dynamics are crucial for the vertical energy transfer in the North Sea due to vertical mixing by wind- and tide-induced shear production (Pohlmann 1996b) and play a decisive role for biogeochemical studies. In our analysis, we use the maximum vertical temperature gradient in the water column to define thermocline parameters and assess their changes.

In the present study, the warming in summer does not strengthen the thermocline by increasing SST. The stronger warming in winter rather leads to a similarly stronger warming of the water masses beneath the thermocline, thus reducing the vertical temperature gradient. Moreover, the analysis indicates a slight decrease in the mean thermocline depth, i.e. a raising of the thermocline, which can be attributed to the slightly weaker mean wind speeds recorded in spring, summer, and autumn. Note that the confidence level of the trend of the mean thermocline depth does not reach statistical significance. Therefore, the inferred causal relation with the similarly insignificant changes in wind speeds is not fully confirmed. However, some evidence can still be drawn indirectly from the significantly increasing maximum thermocline depth, which assigns additional confidence to the changes in wind speed. Under constant wind speeds but a decreasing thermocline intensity, the thermocline would actually deepen. The trend of a slightly raising thermocline shown in Fig. 6 indicates that the change in wind speed even compensates this effect and thus indicates the decreasing wind speeds as the main driver for the mean raise of the thermocline. Likewise, a high level of confidence is associated with the diminishing difference between summer and winter SST due to the strong winter warming, providing additional significance for the lower intensity of the thermocline. A windinduced deepening of the thermocline in late summer is in agreement with Ådlandsvik (2008), and a prolongation of the stratification period was also indicated by Holt et al. (2010).

The higher relative frequency of the thermocline in its southern and western peripheral regions, indicated in Fig. 7, can be attributed to the drop in SSS of Atlantic inflow via the Fair-Isle Passage (by $\sim 0.6 \mathrm{psu}$ ) and the English Channel (by $\sim 0.9 \mathrm{psu}$, see Section 3.5), which increases the vertical density and temperature gradients and thus favors the development of the thermocline. Moreover, lower mean wind speeds allow for higher relative frequencies in the shallow southern North Sea, where bottom friction becomes influential on the stratification. In turn, higher relative frequencies are related to greater mean depths and intensities, also indicated in Fig. 7. As mentioned above, in autumn (September), the lower mean wind speeds and the weaker heat loss to the atmosphere lead to a delay in the thermocline erosion, resulting in higher relative frequencies over the whole thermocline region (up to $35 \%$ in September). The mean depth and intensity of the thermocline consequently also increase in the regions of maximum higher relative frequency, while in the central North Sea, the shallowing of the thermocline due to the lower mean wind speeds dominates. 


\subsection{Salinity}

Furthermore, the intensified hydrological cycle expected under the A1B scenario leads to a considerable freshening in the northern North Atlantic Ocean and hence in the North Sea (IPCC 2007). Additional fresh water sources for the North Sea are in particular the increasing Baltic discharge and the increasing net surface fresh water flux into the ocean, while in our study, river runoff and the Baltic salinity are treated as climatologically constant on the monthly scale. In the absence of a unified North Sea/Baltic Sea model, e.g. as presented by Schrum (2001) or Schrum et al. (2003), Baltic discharge is prescribed with climatological salinity also by Ådlandsvik (2008) and Holt et al. (2010). However, this constraint is unlikely to significantly affect the results in the open North Sea but has a significant impact only along the Norwegian coast. From our model results, we estimated a salinity change in the Baltic outflow by 1 psu to bring about a salinity change in the Norwegian Coastal Current and the entire North Sea by $~ 0.15$ and $0.02 \mathrm{psu}$, respectively.

In our results, the salinity decrease in the North Sea is generally stronger at the sea surface than in deeper layers because of increasing surface fresh water supply and Baltic discharge. These trends tend to intensify the stratification in terms of increasing vertical density gradients and would become even stronger when increasing river runoff and decreasing salinity of the Baltic Sea were incorporated, as in Gröger et al. (2013). In theory, however, the intensifying effect due to the projected increase in the vertical salinity gradient of $\sim 0.1 \mathrm{psu}$ (from their study; change in density gradient $+0.07 \mathrm{~kg} \mathrm{~m}^{-3}$ ) is overcompensated by the weakening effect due to the projected decrease in the vertical temperature gradient of $\sim 0.5^{\circ} \mathrm{C}$ (from our study; change in density gradient $-0.08 \mathrm{~kg} \mathrm{~m}^{-3}$ ), implying a slight weakening of the North Sea stratification.

\section{CONCLUSIONS}

An uncoupled dynamical downscaling of the IPCC SRES scenario A1B was carried out for the North Sea, using the shelf ocean model HAMSOM. The downscaling factors of the horizontal grid resolution amount to $\sim 9$ for the atmospheric forcing and 24 for the open lateral boundary conditions. The differences in the projected climate change signals of seasonal SST indicate that the more accurate simulation of heat fluxes in the RCM leads to a higher temperature trend in winter by $\sim 0.2^{\circ} \mathrm{C}$ and a lower temperature trend in summer by $\sim 0.2^{\circ} \mathrm{C}$ than suggested by the parent GCM. However, general trends projected by the GCM and their qualitative ratio are not changed by the dynamical downscaling. In particular, the stronger warming trend in winter than in summer is also indicated by the GCM in both water and near-surface air temperatures. Nevertheless, the magnitudes of the surface heat fluxes, the formation of the frontal system, and the strength and structure of the general circulation are better represented in the regional meso-scale model. The higher spatial resolution allows more realistic reproductions of horizontal and vertical gradients in the water column. Stronger gradients of water temperature give rise to a more reasonable structure of the thermocline, while stronger gradients of SSH enable simulations of the specific features of the cyclonic North Sea circulation system, which is characterized by strong coastal currents. However, the qualitative agreement in the projected trends between the global and regional model demonstrates the consistency of the used downscaling system. The trend analysis of heat flux components leads to the following major result: the strong warming in winter is the main driver for the total warming of the North Sea and leads to a weakening in the thermal stratification. The comparison with other published dynamical downscaling studies, however, underlines the sensitivity of the presented results to the choice of the parent GCM and its representation of the hydrological cycle. The present study thus contributes to a potentially growing literature-based ensemble study of dynamical downscaling experiments for the North Sea.

Acknowledgements. This work contributed to the EU/ BMBF-funded interdisciplinary MarinERA project ECODRIVE - Ecosystem Change in the North Sea: Processes, Drivers, Future Scenarios. Thanks to the Max-Planck-Institute for Meteorology in Hamburg for providing the relevant MPIOM and REMO model results. Supercomputing resources and data storage capacities have been provided by Deutsches Klimarechenzentrum (DKRZ), Hamburg.

\section{LITERATURE CITED}

Ådlandsvik B (2008) Marine downscaling of a future climate scenario for the North Sea. Tellus 60:451-458

Ådlandsvik B, Bentsen M (2007) Downscaling a twentieth century global climate simulation to the North Sea. Ocean Dyn 57:453-466

Akaike H (1973) Information theory and an extension of the maximum likelihood principle. In: Petrov BN, Csàki F (eds) 2nd Int Symp Information Theory. Akademia Kiadó, Budapest, p 267-281 
Backhaus JO (1985) A three-dimensional model for the simulation of shelf sea dynamics. Dtsch Hydrogr Z 38: 165-187

Backhaus JO (1990) On the atmospherically induced variability of the circulation of the Northwest European Shelf Sea and related phenomena-a model experiment. In: Davies AM (ed) Modeling marine systems, Vol 1. CRC Press, Boca Raton, FL, p 93-134

Bader DC, Covey C, Gutowski WJ Jr, Held IM and others (2008) Climate models: an assessment of strengths and limitations. Department of Energy, Office of Biological and Environmental Research, Washington, DC

Bárdossy A, Pegram G (2011) Downscaling precipitation using regional climate models and circulation patterns toward hydrology. Water Resour Res 47:W04505, doi: 10.1029/2010WR009689

Becker GA, Pauly M (1996) Sea surface temperature changes in the North Sea and their causes. ICES J Mar Sci 53:887-898

Chapman S, Lindzen RS (1970) Atmospheric tides. D. Reidel, Dordrecht

Damm PE (1997) Die saisonale Salzgehalts- und Frischwasserverteilung in der Nordsee und ihre Bilanzierung. Ber ZMK, B, Ozeanographie 28, Inst für Meereskunde, Hamburg

> Delhez EJM, Damm P, de Goede E, de Kok JM and others (2004) Variability of shelf-seas hydrodynamic models: lessons from the NOMADS2 project. J Mar Syst 45:39-53

Déqué M, Jones RG, Wild M, Giorgi F and others (2005) Global high resolution versus Limited Area Model climate change projections over Europe: quantifying confidence level from PRUDENCE results. Clim Dyn 25: 653-670

Déqué M, Somot S, Sanchez-Gomez E, Goodess CM, Jacob D, Lenderink G (2012) The spread amongst ENSEMBLES regional scenarios: Regional Climate Models, driving General Circulation Models and interannual variability. Clim Dyn 38:951-964

Draper NR, Smith H (1998) Applied regression analysis, 3rd edn. John Wiley \& Sons, New York, NY

> Feser F, Rockel B, von Storch H, Winterfeldt J, Zahn M (2011) Regional climate models add value to global model data. A review and selected examples. Bull Am Meteorol Soc 92:1181-1192

Francis JA, Vavrus SJ (2012) Evidence linking arctic amplification to extreme weather in mid-latitudes. Geophys Res Lett 39:L06801, doi:10.1029/2012GL051000

Gröger M, Maier-Reimer E, Mikolajewicz U, Moll A, Sein D (2013) NW European shelf under climate warming: implications for open ocean-shelf exchange, primary production, and carbon absorption. Biogeosciences 10: 3767-3792

$>$ Hawkins E, Sutton R (2009) The potential to narrow uncertainties in regional climate predictions. Bull Am Meteorol Soc 90:1095-1107

Hein B (2012) Processes of stratification and destratification in the Mekong ROFI. PhD dissertation, University of Hamburg

Hjøllo SS, Skogen MD, Svendsen E (2009) Exploring currents and heat within the North Sea using a numerical model. J Mar Syst 78:180-192

Holt J, Wakelin S, Lowe J, Tinker J (2010) The potential impacts of climate change on the hydrography of the northwest European continental shelf. Prog Oceanogr 86:361-379
Holt J, Butenschön M, Wakelin SL, Artioli Y, Allen JI (2012) Oceanic controls on the primary production of the northwest European continental shelf: model experiments under recent past conditions and a potential future scenario. Biogeosciences 9:97-117

IPCC (2007) Climate change 2007: synthesis report. In: Core Writing Team, Pachauri RK, Reisinger A (eds) Contribution of Working Groups I, II and III to the Fourth Assessment Report of the Intergovernmental Panel on Climate Change. IPCC, Geneva

Jacob D (2001) A note to the simulation of the annual and inter-annual variability of the water budget over the Baltic Sea drainage basin. Meteorol Atmos Phys 77 : 61-73

> Jacob D, Podzun R (1997) Sensitivity studies with the regional climate model REMO. Meteorol Atmos Phys 63: 119-129

> Jacob D, van den Hurk BJJM, Andræ U, Elgered G and others (2001) A comprehensive model inter-comparison study investigating the water budget during the BALTEX-PIDCAP period. Meteorol Atmos Phys 77: $19-43$

> Jungclaus JH, Botzet M, Haak H, Keenlyside N and others (2006a) Ocean circulation and tropical variability in the coupled model ECHAM5/MPI-OM. J Clim 19:3952-3972

Jungclaus JH, Haak H, Esch M, Roeckner E, Marotzke J (2006b) Will Greenland melting halt the thermohaline circulation? Geophys Res Lett 33:L17708, doi:10.1029/ 2006GL026815

> Klein H, Lange W, Mittelstaedt E (1994) Tidal and residual currents in the northern North Sea: observations. Dtsch Hydrogr Z 46:5-27

Lenhart HJ, Pohlmann T (1997) The ICES-boxes approach in relation to results of a North Sea circulation model. Tellus Ser A Dyn Meteorol Oceanogr 49:139-160

Luyten PJ, Jones JE, Proctor R (2003) A numerical study of the long- and short-term temperature variability and thermal circulation in the North Sea. J Phys Oceanogr 33:37-56

> Marsland SJ, Haak H, Jungclaus JH, Latif M, Roeske F (2003) The Max-Planck-Institute global ocean/sea ice model with orthogonal curvilinear coordinates. Ocean Model 5:91-127

Mathis M, Mayer B, Pohlmann T (2013) An uncoupled dynamical downscaling for the North Sea: method and evaluation. Ocean Model 72:153-166

> Meier HEM (2006) Baltic Sea climate in the late twenty-first century: a dynamical downscaling approach using two global models and two emission scenarios. Clim Dyn 27: $39-68$

> Melsom A, Lien VS, Budgell WP (2009) Using the Regional Ocean Modeling System (ROMS) to improve the ocean circulation from a GCM 20th century simulation. Ocean Dyn 59:969-981

- Meyer EMI, Pohlmann T, Weisse R (2011) Thermodynamic variability and change in the North Sea (1948-2007) derived from a multidecadal hindcast. J Mar Syst 86:35-44

Nakicenovic N, Swart R (eds) (2000) Special report on emissions scenarios: a special report of Working Group III of the Intergovernmental Panel on Climate Change. Cambridge University Press, Cambridge

O'Driscoll K, Mayer B, Ilyina T, Pohlmann T (2013) Modelling the cycling of persistent organic pollutants (POPs) in the North Sea system: fluxes, loading, seasonality, trends. J Mar Syst 111-112:69-82 
Otto L, Zimmerman JTF, Furnes GK, Mork M, Sætre R, Becker G (1990) Review of the physical oceanography of the North Sea. Neth J Sea Res 26:161-238

Pielke RAS, Wilby RL (2012) Regional climate downscaling: what's the point? Eos Trans AGU 93:52-53

Pohlmann T (1991) Untersuchung hydro- und thermodynamischer Prozesse in der Nordsee mit einem dreidimensionalen numerischen Modell. Ber Zent MeeresKlimaforsch Univ Hambg D 23:1-116

Pohlmann T (1996a) Calculating the annual cycle of the vertical eddy viscosity in the North Sea with a threedimensional baroclinic shelf sea circulation model. Cont Shelf Res 16:147-161

Pohlmann T (1996b) Calculating the development of the thermal vertical stratification in the North Sea with a three-dimensional baroclinic circulation model. Cont Shelf Res 16:163-194

Pohlmann T (1996c) Predicting the thermocline in a circulation model of the North Sea. Part 1. Model description, calibration and verification. Cont Shelf Res 16:131-146

Pohlmann T (2006) A meso-scale model of the central and southern North Sea: consequences of an improved resolution. Cont Shelf Res 26:2367-2385

Roeckner E, Brokopf R, Esch M, Giorgetta M and others (2006) Sensitivity of simulated climate to horizontal and vertical resolution in the ECHAM5 atmosphere model. J Clim 19:3771-3791

Schlünzen KH, Krell U (2004) Atmospheric parameters for the North Sea: a review. Mar Biodivers 34:1-52

Schrum C (2001) Regionalization of climate change for the North Sea and the Baltic Sea. Clim Res 18:31-37

Editorial responsibility: Oliver Frauenfeld,

College Station, Texas, USA
Schrum C, Hübner U, Jacob D, Podzun R (2003) A coupled atmosphere/ice/ocean model for the North Sea and the Baltic Sea. Clim Dyn 21:131-151

Schrum C, Harms I, Hatten K (2005) Modelling air-sea exchange in the Barents Sea by using a coupled regional ice-ocean model. Meteorol Z 14:801-808

Schwarz G (1978) Estimating the dimension of a model. Ann Stat 6:461-464

> Siegismund F, Schrum C (2001) Decadal changes in the wind forcing over the North Sea. Clim Res 18:39-45

Slangen ABA, Katsman CA, van de Wal RSW, Vermeersen LLA, Riva REM (2012) Towards regional projections of twenty-first century sea-level change based on IPCC SRES scenarios. Clim Dyn 38:1191-1209

Solomon S, Qin D, Manning M, Chen Z and others (eds) (2007) Contribution of Working Group I to the Fourth Assessment Report of the Intergovernmental Panel on Climate Change. Cambridge University Press, Cambridge

Sterl A, van den Brink H, de Vries H, Haarsma R, van Meijgaard E (2009) An ensemble study of extreme storm surge related water levels in the North Sea in a changing climate. Ocean Sci 5:369-378

van der Linden P, Mitchell JFB (eds) (2009) ENSEMBLES: climate change and its impacts: summary of research and results from the ENSEMBLES project. Met Office Hadley Centre, Exeter

von Storch H, Zwiers FW (1999) Statistical analysis in climate research. Cambridge University Press, Cambridge

Wilks D (2005) Statistical methods in the atmospheric sciences, Vol 100, 2nd edn. Academic Press, Burlington, MA

Submitted: July 1, 2013; Accepted: April 7, 2014

Proofs received from author(s): July 22, 2014 